\title{
Analysis of the Impact of Disease Acceptance, Demographic, and Clinical Variables on Adherence to Treatment Recommendations in Elderly Type 2 Diabetes Mellitus Patients
}

\author{
Iwona Bonikowska $^{1, *}$, Katarzyna Szwamel ${ }^{2} \mathbb{D}$ and Izabella Uchmanowicz ${ }^{3}$ (D) \\ 1 Institute of Health Sciences, Department Nursing, University of Zielona Góra, 2 Energetyków Street, \\ 65-00 Zielona Góra, Poland \\ 2 Institute of Health Sciences, University of Opole, Katowicka Street 68, 45-060 Opole, Poland; \\ katarzyna.szwamel@uni.opole.pl \\ 3 Faculty of Health Sciences, Wrocław Medical University, K. Bartla 5, 51-618 Wroclaw, Poland; \\ izabella.uchmanowicz@umed.wroc.pl \\ * Correspondence: i.bonikowska@cm.uz.zgora.pl
}

Citation: Bonikowska, I.; Szwamel, K.; Uchmanowicz, I. Analysis of the Impact of Disease Acceptance, Demographic, and Clinical Variables on Adherence to Treatment Recommendations in Elderly Type 2 Diabetes Mellitus Patients. Int. J. Environ. Res. Public Health 2021, 18, 8658. https:// doi.org/10.3390/ijerph18168658

Academic Editors: Aurea Grané and Irene Albarrán

Received: 22 June 2021

Accepted: 9 August 2021

Published: 16 August 2021

Publisher's Note: MDPI stays neutral with regard to jurisdictional claims in published maps and institutional affiliations.

Copyright: (c) 2021 by the authors. Licensee MDPI, Basel, Switzerland. This article is an open access article distributed under the terms and conditions of the Creative Commons Attribution (CC BY) license (https:/ / creativecommons.org/licenses/by/ $4.0 /)$.

\begin{abstract}
This project aimed to analyze the impact of disease acceptance and selected demographic and clinical factors on the adherence to treatment recommendations in elderly type 2 diabetes mellitus patients. The observational study was performed using standardized research questionnaires: the Acceptance of Illness Scale (AIS), the Self-Care of Diabetes Inventory (SCODI), and the Adherence in Chronic Diseases Scale $(A C D S)$. Two hundred patients with T2DM were studied (age $\mathrm{M}=70.21$ years, $\mathrm{SD}=6.63$ years). The median degree of disease acceptance was $29(\min -\max =8-40)$ and the median level of adherence was $24(\min -\max =13-28)$. Disease acceptance was a significant $(p=0.002)$ independent predictor of the odds of qualifying for non-adherence OR $=0.903,95 \% \mathrm{CI}=0.846-0.963$. The respondents gave the lowest scores for glycemic control $(\mathrm{Mdn}=38.99$, $\min -\max =8.33-150)$, and health control $(\mathrm{Mdn}=55.88, \min -\max =11.76-100)$. A one-way ANOVA showed that the non-adhering patients were significantly older compared to the adherence group and were taking significantly more diabetes pills per day. The level of disease acceptance was average, but it turned out to be an independent predictor of adherence. Therefore, it is justified to use psychological and behavioral interventions that are aimed at increasing the level of diabetes acceptance in elderly people with T2DM. It is important to have a holistic approach to the patient and to take actions that consider the patient's deficits in the entire biopsychosocial sphere. The obtained result confirmed the legitimacy of interventions aimed at increasing the level of disease acceptance in this group of patients.
\end{abstract}

Keywords: type 2 diabetes mellitus; compliance; adherence; aged

\section{Introduction}

Type 2 diabetes mellitus (T2DM) is one of the most common chronic conditions among older people. Patient acceptance of their illness is the most vital goal in the management of chronic illnesses. Type 2 diabetes accounts for around $90 \%$ of all people with diabetes [1]. Population growth, environmental and lifestyle changes, and aging populations are generally believed to account for the rapid global increase in the number of people with T2DM in recent decades [2]. Currently, the largest number of elderly people with diabetes live in China (35.5 million), the USA (14.6 million), India (12.1 million), and Germany (6.3 million) [3]. In Poland in 2018, 2.86 million adults (9.1\%) suffered from diabetes, $84 \%$ of which were people aged 55 and over [4]. Diabetes among the aged in our societies places a tremendous health burden on older individuals and is likely to continue to stretch the financial resources and social care services on a global scale [3]. The analysis of healthcare costs related to diabetes treatment showed that diabetes was responsible for an estimated USD 
760 billion in health expenditure in 2019, with the highest annual costs being generated by the elderly (60-69 years with USD 177.7 billion and 70-79 years with USD 171.5 billion) [5].

T2DM is one of the most common chronic conditions among older people [3]. It is also one of the main causes of premature disability, blindness, terminal chronic kidney disease, and nontraumatic amputations, as well as being a frequent cause of hospitalization [6]. Prolonged duration of the disease and decreased organ reserves make older adults with diabetes particularly susceptible to stroke, heart disease, retinopathy, nephropathy, and neuropathy $[7,8]$. Previous research also showed that those aged 75 years and above experience double the rate of emergency department visits for hypoglycemia than the general population with diabetes [9]. People with diabetes are at higher risk of death and lower life expectancy compared to the general population $[10,11]$. It was shown that for people above 80 years of age, the comorbidity of heart failure, the presence of cognitive impairment, and the absence of statin therapy are important predictors of mortality in patients with DM [12].

The treatment of T2DM involves controlling blood glucose levels, a healthy diet, physical activity, the management of risk factors that can contribute to the damage of blood vessels, and a complex therapeutic regimen (oral hypoglycemic medications and insulin therapy) [13]. Many studies showed that poor adherence to the medical regimen is a major clinical problem in the management of patients with diabetes [14-17]. In developed nations, approximately $50 \%$ of diabetic patients do not adhere to the recommended therapies [14]. Adherence is defined as "the extent to which a person's behavior, taking medication, following a diet, and /or executing lifestyle changes, corresponds with agreed recommendations from a health care provider" [18]. There are many factors related to therapeutic non-adherence among patients with diabetes, such as sociodemographic characteristics, medication, physical and mental health, and the healthcare system. Researchers indicated that factors associated with poor adherence among diabetics include: being older than 60 , being of non-European origin, having financial difficulties, being professionally active, having inadequate patient education, being in a low monthly income bracket, having a low level of education, the number of years since being diagnosed (individuals with three years or more since being medically diagnosed with diabetes were more likely to be adherent), the existence of any side effects from their medications, the complexity of their treatment regimen, unavailability of medicines, the high cost of medications, forgetfulness, the disappearance of symptoms, irregularity of follow-ups, lack of transportation, absence of a home glucometer, an $\mathrm{HbA} 1 \mathrm{c}$ of $8 \%$, existing diabetes complications, having a high level of anxiety, depression and/or alcohol consumption [17,19-22]. Jaam et al. [23] proposed a holistic conceptual framework model to describe medication adherence and guide interventions in diabetes mellitus. The authors distinguished six main factors in patients' behavior toward medications adherence: patient-related factors, diabetes-related factors, medication-related factors, healthcare-provider-related factors, healthcare-system-related factors, and societalrelated factors. In the group of "patient-related factors," the researchers included the following factors: specific demographics, knowledge (about medication, about the disease, ability to read the medication label, training), comorbidities, quality of life, psychological feelings, beliefs and perceptions (e.g., effectiveness of medications, seriousness of the disease, religious beliefs, and fatalistic beliefs), and other factors (e.g., forgetfulness and medication-taking routine) Both the adherence model described above and the literature cited above describing the determinants of adherence in T2DM patients do not take into account a very important patient-related factor, namely, the degree of disease acceptance. Our research takes this factor into account, which makes it innovative in this respect.

The individual's acceptance of the illness is the most vital goal in the management of chronic illnesses [24]. Acceptance of one's illness is a psychological indicator of the quality of adaptation to life with a disease. Achieving optimal adaptation to chronic disease is essential, especially for diseases that cannot be cured. The process of adaptation to disease begins when the patient is informed about a chronic disease diagnosis [25]. Adaptation to disease is a dynamic, complex process that changes over time, depending on 
the changes in the patient's clinical or psychosocial situation [26]. Although the patient is forced to live with diabetes, the disease is mostly not accepted due to the threat of serious complications [27]. In the process of adaptation to disease, a central role is assigned to cognitive assessment, mainly to the belief about control [28]. However, in older people living with T2DM, the cognitive condition is correlated to specific topics of health literacy, such as nutritional status, physical activity, and medication adherence, which further complicates adaptation to the disease and adherence to the recommended therapies.

Taking into account the complexity of the phenomenon of adherence to treatment recommendations in elderly people with $\mathrm{T} 2 \mathrm{DM}$, it was considered necessary to understand it more deeply by establishing the degree of disease acceptance, the levels of self-care and adherence, and significant predictors of adherence. It was assumed in the study that the acceptance of a chronic disease determines the level of compliance with treatment recommendations in elderly patients with T2DM. Understanding this dependence may allow for taking actions that are aimed at improving the patient's self-control and participation in the therapeutic process.

This project aimed to analyze the impact of disease acceptance and selected demographic and clinical factors on adherence to treatment recommendations in elderly type 2 diabetes mellitus patients. We aimed to answer the following research questions: What is the degree of disease acceptance, the self-care level, and the adherence level in the group of elderly patients with T2DM? Is there any association between disease acceptance and adherence to treatment recommendations and self-care level? Are there any significant predictors of the adherence level in the study group?

\section{Materials and Methods}

\subsection{Design}

Observational studies were conducted among the inhabitants of the Lubuskie Voivodeship (Poland). This publication presents only a part of the results of a larger research project entitled "Adherence to treatment recommendations by elderly patients with type 2 diabetes." This project aimed to analyze the influence of selected demographic and clinical factors on compliance with the therapeutic recommendations of elderly T2DM patients. The results of the study will contribute toward taking measures to improve self-control and improve patient participation in the therapeutic process (adherence, compliance). This study focused mainly on showing the influence of disease acceptance on adherence and determining the predictors of this phenomenon.

\subsection{Setting}

The study was conducted in the period from November 2018 to December 2019. The study was conducted among patients of five primary healthcare facilities located in the Zielona Góra poviat (Lubuskie Voivodeship, Poland).

Stage I of the study consisted of selecting patients with T2DM. A cover letter was sent to the heads of primary healthcare facilities in Zielona Góra and the Zielona Góra poviat, asking for consent to conduct the study. Out of 30 primary healthcare units, 5 gave their consent in writing. Doctors identified patients for the study according to the inclusion criteria. Then, the interviewer (a diabetes nurse) interviewed the patient, presenting the purpose and method of the study and obtaining preliminary oral informed consent. Patients received a complete set of questionnaires and a written informed consent form to participate in the study. Patients had a choice of two options to fill in the form: directly in the healthcare center or by correspondence. Patients filled in the questionnaires themselves. Ultimately, only those patients who signed the specially prepared informed consent form for the study were included in the study. Then, the collected questionnaires were verified for correctness of completion and subjected to statistical analysis. 


\subsection{Respondents}

The inclusion criteria for the study were: age $\geq 60$ years, time from the diagnosis of T2DM of at least one year, written consent to conduct the study, practical means of contact with the patient, no diagnosis of severe mental disorders requiring psychiatric treatment. The exclusion criteria were: age $<60$ years, severe exacerbation of T2DM or comorbid disease (severe patient condition, hemodynamic instability), diagnosis of severe psychiatric disorders requiring psychiatric treatment, and no written consent to participate in the study.

Before the study, each respondent was informed about the purpose of the study, the method to be used, and the possibility of withdrawal at each stage. The patients were assured of their anonymous and voluntary participation in the study.

\subsection{Variables}

To achieve the assumed goals and conduct statistical analyses, 4 groups of variables were distinguished:

(a) Demographic variables: age, sex, education, place of residence, and marital status.

(b) Clinical variables: duration of disease, diabetes treatment method, presence and type of comorbidities, BMI, number of diabetes tablets per day, and the total number of tablets taken per day.

(c) Psychological variables: the degree of acceptance of the AIS disease.

(d) Self-care variables: health behavior (maintaining self-care), health control (monitoring self-care), glucose control (self-care management), and self-confidence in managing self-care.

(e) Adherence to treatment recommendations variable: adherence level.

\subsection{Study Size}

Based on the data of the Lubuskie Department of the National Health Fund from 2018, the number of patients with diagnoses of ICD-10 (E11-E11.9) in the age range of 60-89 years treated in the Lubuskie Voivodeship in 2017 was 39,197 patients, which accounted for $68 \%$ of the entire population of patients diagnosed with diabetes in this area [29]. In our study, we used a non-probabilistic sampling method (purposive sampling).

Initially, 280 patients meeting the inclusion criteria were invited into the study. A total of 250 patients accepted the invitation. Fifty patients who completed questionnaires incorrectly were excluded from the study. Finally, the data of 200 patients with T2DM, whose mean age was 70.21 years $(\mathrm{SD}=6.63$ years), were analyzed. Out of the original 280 patients, 200 patients were eventually enrolled in the study due to the lack of the patient's written consent and/or deficiencies in completed forms (Figure 1).

\subsection{Data Sources/Measurement}

The study was conducted with the use of a diagnostic survey with the questionnaire technique using standardized questionnaires: the Acceptance of Illness Scale (AIS), the Self-Care of Diabetes Inventory (SCODI), the Adherence in Chronic Diseases Scale (ACDS), and the questionnaire developed by the authors for sociodemographic and clinical data.

The Acceptance of Illness Scale (AIS) (Table S1) can be used to assess the degree of acceptance of every disease. The scale was originally constructed by Felton et al. and adapted to the Polish conditions by Juczyński [28]. The Cronbach $\alpha$ coefficient of the Polish version is 0.85 and that of the original version is 0.82 . The AIS consists of eight statements about the negative consequences of the state of health. Every statement is rated on a five-point Likert-type scale ( 1 denotes poor adaptation to disease and 5 denotes its full acceptance). The score for illness acceptance is a sum of all points and can range from 8 to 40 [28]. 


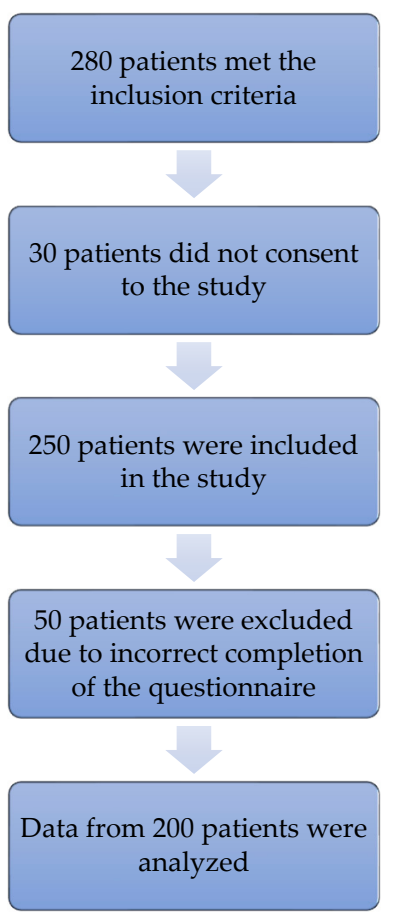

Figure 1. Diagram of the study group selection, taking into account the inclusion and exclusion criteria.

The Self-Care of Diabetes Inventory (SCODI) (Table S2) was used to assess the selfcare level of those with diabetes. The tool consists of 40 SCODI items (5-point Likert scale) that are grouped into four dimensions: maintaining self-care-health behavior (12 items), self-care monitoring — health control (9 items), self-care management-blood glucose control (8 items), and self-confidence in managing self-care (11 items). Each of the four parts of the scale is rated separately and standardized to a 0-100 scale, with higher scores indicating better self-care. Larger numbers stand for greater independence in a given area. The overall consistencies for individual scales were assessed using Cronbach's alpha: self-care maintenance (0.759), self-care monitoring (0.741), self-care management (0.695), and self-care confidence (0.932). The SCODI questionnaire has acceptable internal consistency and reliability when assessing self-care among diabetic patients in the Polish population $[30,31]$.

The Adherence Scale in Chronic Diseases (Table S3) (ACDS) assesses adherence by adults treated for chronic diseases. The premise of ACDS is that only high adherence reflects a good implementation of the pharmacotherapy therapeutic plan. The scale contains 7 questions with proposed sets of 5 answers to each question. The questions relate to behaviors that directly determine adherence (questions $1-5$ ) and to situations and views that may indirectly influence adherence (questions 6-7). The ACDS scores are in the range of 0-28 points. The higher the scores, the higher the adherence level. The results are interpreted as follows: above 26 points-high adherence, between 21 and 26 pointsmedium adherence, and below 21 points-low adherence [32].

According to the definition of the Central Statistical Office, "elderly people" are people aged at least 60 or 65 (depending on the sex). In Poland, the post-productive age begins with retirement, i.e., for men -65 and more, for women -60 and more [33]. In our criteria, we adopted a consistent age of qualification for the examination of a patient; for both women and men, we used 60 years.

The BMI (body mass index) was calculated as a person's weight in kilograms divided by the square of their height in meters. We classified BMI into the following categories: normal body weight was BMI $18.5-24.9 \mathrm{~kg} / \mathrm{m}^{2}$, overweight was BMI $25.0-29.9 \mathrm{~kg} / \mathrm{m}^{2}$ and obesity was diagnosed if BMI $>30 \mathrm{~kg} / \mathrm{m}^{2}$. Obesity is frequently subdivided into categories: 
class 1 -BMI of $30 \mathrm{~kg} / \mathrm{m}^{2}$ to $<35 \mathrm{~kg} / \mathrm{m}^{2}$, class 2 -BMI of $35 \mathrm{~kg} / \mathrm{m}^{2}$ to $<40 \mathrm{~kg} / \mathrm{m}^{2}$, and class 3 -BMI of $40 \mathrm{~kg} / \mathrm{m}^{2}$ or higher [34].

\subsection{Analysis}

The analysis of quantitative variables was performed by calculating the mean, standard deviation, median, quartiles, minimum, and maximum. The analysis of the qualitative variables was performed by calculating the number and percentage of the occurrences of each value. Comparison of the values of qualitative variables in the groups was performed using the chi-square test (with Yates's correction for $2 \times 2$ tables) or the Fisher's exact test where low expected frequencies appeared in the tables. On the other hand, the comparison of the values of quantitative variables in the two groups was performed using the Mann-Whitney test. In turn, the comparison of the values of quantitative variables in the three groups was performed using the Kruskal-Wallis test. Post-hoc analysis with Dunn's test was performed to identify statistically significantly different groups after detecting statistically significant differences.

The multivariate analysis of the independent influence of many variables on the quantitative variable was performed using the linear regression method. The results are presented in the form of values of the regression model parameters with a $95 \%$ confidence interval. For the linear regression and to analyze the similarities and differences between the groups of patients in terms of adherence levels, patients were divided into two groups. Patients with a high adherence level (27-28 points on the ACDS scale) were included in the "adherent" group, while patients with low ( $<21$ points on the ACDS scale) and intermediate adherence (21-26 points) were included in the "non-adherent" group.

The normality of the distribution of quantitative variables was checked with the Shapiro-Wilk test. All quantitative variables did not follow the normal distribution. A critical significance level of 0.05 was used in this study. Analyses were performed using the R software, version 4.0.3.

The approval of the Bioethics Committee was obtained and the requirements of the Helsinki Declaration of 1975 (amended in 2000) and Good Clinical Practice were met.

\section{Results}

\subsection{Demographic and Clinical Characteristics of the Study Group}

The median age of the respondents was 69 years (IQR $=65-74$ years). Most of the respondents were women $(101,50.5 \%)$, people living in relationships $(135,67.5 \%)$, with secondary education $(93,46.5 \%)$, and living in cities $(179,89.5 \%)$. The median duration of diabetes was 10 years (IQR $=5-15$ years). The most frequently used treatment method in the study group was taking oral diabetic medications $(123,61.5 \%)$. The median number of diabetes tablets per day was $2(\mathrm{IQR}=1-3)$. In addition to T2DM, patients suffered from other chronic diseases, most often hypertension $(161,80.5 \%)$, eye diseases $(83,41.5 \%)$, and ischemic heart disease $(71,35.5 \%)$. Most of the respondents were overweight $(76,38.0 \%)$ or had class 1 obesity $(65,32.5 \%)$ (Table 1$)$.

Table 1. Study group characteristics $(n=200)$.

\begin{tabular}{|c|c|c|}
\hline \multicolumn{2}{|c|}{ Demographic Variables } & \multirow{2}{*}{$\begin{array}{c}\text { Values } \\
70.21 \pm 6.63\end{array}$} \\
\hline \multirow{3}{*}{ Age (years) } & $\mathrm{M} \pm \mathrm{SD}^{1}$ & \\
\hline & $\operatorname{Mdn}^{2}$ & 69 \\
\hline & Q.25-Q.75\% ${ }^{3}$ & $65-74$ \\
\hline \multirow{2}{*}{ Sex } & Female & $101(50.5 \%)$ \\
\hline & Male & $99(49.5 \%)$ \\
\hline \multirow{2}{*}{ Marital status } & Single & $65(32.5 \%)$ \\
\hline & In a relationship & $135(67.5 \%)$ \\
\hline
\end{tabular}


Table 1. Cont.

\begin{tabular}{|c|c|c|}
\hline \multicolumn{2}{|c|}{ Demographic Variables } & Values \\
\hline \multirow{4}{*}{ Education } & Elementary & $21(10.5 \%)$ \\
\hline & Vocational & $49(24.5 \%)$ \\
\hline & Secondary & $93(46.5 \%)$ \\
\hline & Higher & $37(18.5 \%)$ \\
\hline \multirow{2}{*}{ Place of residence } & Countryside & $21(10.5 \%)$ \\
\hline & City/town & $179(89.5 \%)$ \\
\hline \multicolumn{2}{|c|}{ Clinical Variables } & Values \\
\hline \multirow{3}{*}{ Duration of diabetes (years) } & $\mathrm{M} \pm \mathrm{SD}$ & $11.79 \pm 8.36$ \\
\hline & Mdn & 10 \\
\hline & Q.25-Q.75\% & $5-15$ \\
\hline \multirow{4}{*}{ Diabetes treatment method } & Oral diabetes medications & $123(61.5 \%)$ \\
\hline & Insulin & $33(16.5 \%)$ \\
\hline & Oral medications + insulin & $38(19.0 \%)$ \\
\hline & Non-pharmacological methods & $6(3.0 \%)$ \\
\hline \multirow{3}{*}{ Number of diabetes tablets per day } & $\mathrm{M} \pm \mathrm{SD}$ & $1.86 \pm 1.42$ \\
\hline & Mdn & 2 \\
\hline & Q.25-Q.75\% & $1-3$ \\
\hline \multirow{3}{*}{ Number of all tablets per day } & $\mathrm{M} \pm \mathrm{SD}$ & $7.86 \pm 4.45$ \\
\hline & Mdn & 7 \\
\hline & Q.25-Q.75\% & $5-10$ \\
\hline \multirow{4}{*}{ Body mass index (BMI) } & Normal weight & $22(11.0 \%)$ \\
\hline & Overweight & $76(38.0 \%)$ \\
\hline & Obesity—class 1 & $65(32.5 \%)$ \\
\hline & Obesity_class 2/class 3 & $37(18.5 \%)$ \\
\hline \multirow{2}{*}{ Comorbidities: Hypertension } & No & $39(19.5 \%)$ \\
\hline & Yes & $161(80.5 \%)$ \\
\hline \multirow{2}{*}{ Comorbidities: Ischemic heart disease } & No & $129(64.5 \%)$ \\
\hline & Yes & $71(35.5 \%)$ \\
\hline \multirow{2}{*}{ Comorbidities: Rheumatic diseases } & No & $150(75.0 \%)$ \\
\hline & Yes & $50(25.0 \%)$ \\
\hline \multirow{2}{*}{ Comorbidities: Renal diseases } & No & $163(81.5 \%)$ \\
\hline & Yes & $37(18.5 \%)$ \\
\hline \multirow{2}{*}{ Comorbidities: Respiratory diseases } & No & $159(79.5 \%)$ \\
\hline & Yes & $41(20.5 \%)$ \\
\hline \multirow{2}{*}{ Comorbidities: Diseases of the locomotor system } & No & $135(67.5 \%)$ \\
\hline & Yes & $65(32.5 \%)$ \\
\hline \multirow{2}{*}{ Comorbidities: Diabetic foot syndrome } & No & $157(78.5 \%)$ \\
\hline & Yes & $43(21.5 \%)$ \\
\hline \multirow{2}{*}{ Comorbidities: Eye diseases } & No & $117(58.5 \%)$ \\
\hline & Yes & $83(41.5 \%)$ \\
\hline
\end{tabular}

Legend: $\mathrm{M} \pm \mathrm{SD}^{1}$-mean \pm standard deviation, ${ }^{2}$ median, ${ }^{3}$ first quartile and third quartile.

3.2. The Degree of Disease Acceptance, Self-Care Level Regarding Diabetes, and Adherence Level

The median degree of disease acceptance was $29(\min -\max =8-40)$. The median adherence level was 24 ( $\min -\max =13-28)$. Out of the 200 survey respondents, a group of $114(57.0 \%)$ people had average adherence (21-26 points), 44 respondents $(22.0 \%)$ had 
high adherence (27-28 points), and 42 respondents $(21.0 \%)$ had low adherence ( $<21$ points). Respondents were best at complying with the recommendations regarding proper health behavior $(\mathrm{Mdn}=68.75, \min -\max =31.25-100)$ and maintaining self-confidence $(\mathrm{Mdn}=68.18, \min -\max =15.91-100)$, they were slightly worse at health control $(\mathrm{Mdn}=55.88, \min -\max =11.76-100)$, and were worst at glucose control $(\mathrm{Mdn}=38.99$, $\min -\max =8.33-150)($ Table 2$)$.

Table 2. Average measures for the degree of disease acceptance, self-care level regarding their diabetes, and adherence level.

\begin{tabular}{|c|c|c|c|c|c|c|c|c|c|}
\hline & Tool & $\mathbf{n}$ & $\mathbf{M}^{4}$ & $\mathrm{SD}^{5}$ & $\operatorname{Mdn}^{6}$ & $\operatorname{Min}^{7}$ & $\operatorname{Max}^{8}$ & $Q .25 \%{ }^{9}$ & $Q .75 \% 10$ \\
\hline & $\mathrm{ACDS}^{1}$ & 200 & 23.4 & 3.66 & 24 & 13 & 28 & 21 & 26 \\
\hline & AIS $^{2}$ & 200 & 28.52 & 7.48 & 29 & 8 & 40 & 24 & 34 \\
\hline \multirow{4}{*}{$\stackrel{\infty}{\stackrel{\infty}{0}}$} & $\begin{array}{c}\text { Health behavior } \\
\text { (self-care maintenance) }\end{array}$ & 200 & 68.35 & 15.41 & 68.75 & 31.25 & 100 & 58.33 & 77.60 \\
\hline & $\begin{array}{c}\text { Health control } \\
\text { (self-care monitoring) }\end{array}$ & 200 & 58.49 & 23.00 & 55.88 & 11.76 & 100 & 41.18 & 77.21 \\
\hline & $\begin{array}{c}\text { Glucose control } \\
\text { (self-care management) }\end{array}$ & 200 & 40.68 & 22.15 & 38.89 & 8.33 & 150 & 22.22 & 55.56 \\
\hline & $\begin{array}{c}\text { Self-confidence } \\
\text { in self-care management }\end{array}$ & 200 & 65.84 & 19.41 & 68.18 & 15.91 & 100 & 50.00 & 80.11 \\
\hline
\end{tabular}

Legend: ${ }^{1}$ Adherence in Chronic Diseases Scale, ${ }^{2}$ Acceptance of Illness Scale, ${ }^{3}$ Self-Care of Diabetes Inventory, ${ }^{4}$ mean, ${ }^{5}$ standard deviation, ${ }^{6}$ median, ${ }^{7}$ minimum, ${ }^{8}$ maximum, ${ }^{9}$ first quartile, ${ }^{10}$ third quartile.

\subsection{Influence of Disease Acceptance on the Adherence to Therapeutic Recommendations and Self-Care Level}

The disease acceptance level was significantly higher in the high adherence group than in the low and medium adherence groups $(p=0.002)$ (Table 3$)$.

Table 3. Disease acceptance level and adherence to therapeutic recommendations in elderly patients with T2DM.

\begin{tabular}{|c|c|c|c|c|}
\hline \multirow[b]{2}{*}{ AIS $^{2}$ (Points) } & \multicolumn{3}{|c|}{$\operatorname{ACDS}^{1}$} & \multirow[b]{2}{*}{$p$} \\
\hline & $\begin{array}{c}\text { Low Adherence } \\
\begin{array}{c}(\mathrm{n}=42) \\
\mathrm{A}\end{array}\end{array}$ & $\begin{array}{l}\text { Average Adherence } \\
\qquad(\mathrm{n}=114) \\
\text { B }\end{array}$ & $\begin{array}{c}\text { High Adherence } \\
(\mathrm{n}=44) \\
\text { C }\end{array}$ & \\
\hline $\mathrm{M} \pm \mathrm{SD}^{3}$ & $26.98 \pm 8.05$ & $27.83 \pm 6.78$ & $31.8 \pm 7.86$ & \multirow{3}{*}{$\begin{array}{c}p=0.002 \\
C>B, A\end{array}$} \\
\hline $\operatorname{Mdn}^{4}$ & 29 & 29 & 33 & \\
\hline Q.25-Q.75\% ${ }^{5}$ & $21-33$ & $21-33$ & $25-38.5$ & \\
\hline
\end{tabular}

Legend: ${ }^{1}$ Adherence in Chronic Diseases Scale, ${ }^{2}$ Acceptance of Illness Scale, ${ }^{3}$ mean \pm standard deviation,

${ }^{4}$ median, ${ }^{5}$ first quartile and third quartile, ${ }^{*}$ Kruskal-Wallis test + post hoc analysis (Dunn's test).

The level of disease acceptance significantly positively correlated with health control $(r=0.186, p=0.009)$ and glucose control $(r=0.201, p=0.004)$; along with the increase in the level of disease acceptance, independence of the studied patients in these control areas increased. The level of disease acceptance did not correlate significantly with health behavior $(r=0.103, p=0.149)$ or with self-confidence $(r=0.134, p=0.059)$ (Table 4$)$. 
Table 4. Disease acceptance and the level of self-care.

\begin{tabular}{cc}
\hline SCODI $^{1}$ & AIS $^{2}$ \\
\cline { 2 - 2 } & Spearman's Correlation Coefficient $^{\text {2 }}$ \\
\hline Health behavior & $r=0.103, p=0.149$ \\
\hline Health control & $r=0.186, p=0.009^{*}$ \\
\hline Glucose control & $r=0.201, p=0.004^{*}$ \\
\hline Self-confidence & $r=0.134, p=0.059$
\end{tabular}

Legend: * Statistically significant relationship $(p<0.05),{ }^{1}$ Self-Care of Diabetes Inventory, ${ }^{2}$ Acceptance of Illness Scale.

\subsection{Factors Determining the Adherence Level-Multivariate Analysis}

The multivariate logistic regression model showed that the disease acceptance level $(\mathrm{OR}=0.903,95 \% \mathrm{CI}=0.846-0.963)$ was a significant $(p=0.002)$ independent predictor of the chance of qualifying for the "non-adherent" group, where each "disease acceptance point" lowered the chance of qualifying for the "non-adherent" group by $9.7 \%$ (Table 5).

Table 5. Non-adherence predictors-multivariate logistic regression model.

\begin{tabular}{|c|c|c|c|c|c|}
\hline \multicolumn{2}{|c|}{ Variable } & \multirow{2}{*}{$\begin{array}{l}\text { OR }^{1} \\
0.903\end{array}$} & \multicolumn{2}{|c|}{$95 \% \mathrm{CI}$} & \multirow{2}{*}{$\frac{p}{0.002 *}$} \\
\hline AIS & (points) & & 0.846 & 0.963 & \\
\hline Age & (years) & 1.058 & 0.974 & 1.15 & 0.181 \\
\hline \multirow{2}{*}{ Sex } & Female & 1 & ref. & & \\
\hline & Male & 2.269 & 0.888 & 5.8 & 0.087 \\
\hline \multirow{2}{*}{ Marital status } & Single & 1 & ref. & & \\
\hline & In a relationship & 0.586 & 0.202 & 1.698 & 0.325 \\
\hline \multirow{4}{*}{ Education } & Elementary & 1 & ref. & & \\
\hline & Vocational & 1.359 & 0.244 & 7.587 & 0.726 \\
\hline & Secondary & 0.881 & 0.179 & 4.335 & 0.877 \\
\hline & Higher & 1.537 & 0.241 & 9.794 & 0.649 \\
\hline \multirow{2}{*}{ Place of residence } & Countryside & 1 & ref. & & \\
\hline & City/town & 1.542 & 0.376 & 6.329 & 0.548 \\
\hline \multirow{4}{*}{ BMI } & Normal weight & 1 & ref. & & \\
\hline & Overweight & 0.367 & 0.059 & 2.265 & 0.28 \\
\hline & Obesity_class 1 & 0.344 & 0.049 & 2.402 & 0.282 \\
\hline & Obesity_class 2 /class 3 & 0.466 & 0.054 & 4.007 & 0.487 \\
\hline \multirow{2}{*}{$\begin{array}{l}\text { Comorbidities: } \\
\text { Arterial hypertension }\end{array}$} & No & 1 & ref. & & \\
\hline & Yes & 1.082 & 0.305 & 3.84 & 0.903 \\
\hline \multirow{2}{*}{$\begin{array}{l}\text { Comorbidities: } \\
\text { Ischemic heart disease }\end{array}$} & No & 1 & ref. & & \\
\hline & Yes & 0.497 & 0.187 & 1.32 & 0.161 \\
\hline \multirow{2}{*}{$\begin{array}{c}\text { Comorbidities: } \\
\text { Rheumatic diseases }\end{array}$} & No & 1 & ref. & & \\
\hline & Yes & 0.896 & 0.294 & 2.729 & 0.847 \\
\hline \multirow{2}{*}{$\begin{array}{l}\text { Comorbidities: } \\
\text { Renal diseases }\end{array}$} & No & 1 & ref. & & \\
\hline & Yes & 1.816 & 0.495 & 6.661 & 0.368 \\
\hline \multirow{2}{*}{$\begin{array}{c}\text { Comorbidities: } \\
\text { Respiratory diseases }\end{array}$} & No & 1 & ref. & & \\
\hline & Yes & 1.094 & 0.351 & 3.406 & 0.877 \\
\hline
\end{tabular}


Table 5. Cont.

\begin{tabular}{|c|c|c|c|c|c|}
\hline \multicolumn{2}{|l|}{ Variable } & \multirow{2}{*}{$\begin{array}{c}\text { OR }^{\mathbf{1}} \\
1\end{array}$} & \multicolumn{2}{|c|}{$95 \% \mathrm{CI}$} & \multirow[t]{2}{*}{$p$} \\
\hline \multirow{2}{*}{ Comorbidities: Diseases of the locomotor system } & No & & ref. & & \\
\hline & Yes & 0.845 & 0.339 & 2.107 & 0.717 \\
\hline \multirow{2}{*}{$\begin{array}{l}\text { Comorbidities: } \\
\text { Diabetic foot syndrome }\end{array}$} & No & 1 & ref. & & \\
\hline & Yes & 0.691 & 0.217 & 2.201 & 0.531 \\
\hline \multirow{2}{*}{$\begin{array}{l}\text { Comorbidities: } \\
\text { Eye diseases }\end{array}$} & No & 1 & ref. & & \\
\hline & Yes & 0.752 & 0.299 & 1.892 & 0.545 \\
\hline Duration of the disease & (years) & 1.05 & 0.98 & 1.125 & 0.168 \\
\hline \multirow{4}{*}{ Diabetes treatment method } & Oral diabetes medications & 1 & ref. & & \\
\hline & Insulin & 1.433 & 0.225 & 9.134 & 0.703 \\
\hline & Oral medications + insulin & 0.637 & 0.182 & 2.231 & 0.48 \\
\hline & $\begin{array}{c}\text { Non-pharmacological } \\
\text { methods }\end{array}$ & 0.998 & 0.061 & 16.241 & 0.999 \\
\hline \multicolumn{2}{|c|}{ Number of diabetes tablets per day } & 1.708 & 0.857 & 3.401 & 0.128 \\
\hline \multicolumn{2}{|c|}{ Number of all tablets per day } & 1.001 & 0.879 & 1.141 & 0.987 \\
\hline
\end{tabular}

Legend: ${ }^{1}$ odds ratio, $p$-multivariate logistic regression, ${ }^{*}$ statistically significant relationship $(p<0.05)$.

Age and number of diabetes medications were significantly different between patients in the "adherent" and "non-adherent" groups. Patients in the "non-adherent" group were significantly older compared to those in the "adherent" group (Mdn = 69 years, $\mathrm{IQR}=66-76$ years vs. $\mathrm{Mdn}=67$ years, $\mathrm{IQR}=64-71.5$ years, $p=0.016$ ). Patients in the "nonadherent" group took a significantly greater number of diabetes tablets per day compared to the "adherent" group $(\mathrm{Mdn}=2, \mathrm{IQR}=1-3$ tablets vs. $\mathrm{Mdn}=1.5, \mathrm{IQR}=1-2$ tablets) (Table 6).

Table 6. Adherent and non-adherent patients—univariate analysis.

\begin{tabular}{|c|c|c|c|c|}
\hline \multirow[b]{2}{*}{ Variable } & & \multicolumn{2}{|c|}{$\operatorname{ACDS}^{1}$} & \multirow[b]{2}{*}{$p$} \\
\hline & & $\begin{array}{l}\text { Adherent } \\
(\mathrm{n}=44)\end{array}$ & Non-Adherent $(\mathrm{n}=156$ ) & \\
\hline \multirow{3}{*}{ Age (years) } & $\mathrm{M} \pm \mathrm{SD}^{2}$ & $68.36 \pm 6.37$ & $70.73 \pm 6.63$ & \multirow{3}{*}{$p=0.016^{*}$} \\
\hline & $\operatorname{Mdn}^{3}$ & 67 & 69 & \\
\hline & Q.25-Q.75\% ${ }^{4}$ & $64-71.5$ & $66-76$ & \\
\hline \multirow{3}{*}{ Duration of the disease (years) } & $\mathrm{M} \pm \mathrm{SD}$ & $9.52 \pm 6.34$ & $12.42 \pm 8.75$ & \multirow{3}{*}{$p=0.063$} \\
\hline & Mdn & 9 & 10 & \\
\hline & Q.25-Q.75\% & $5-12.5$ & $5-17.25$ & \\
\hline \multirow{3}{*}{ Number of diabetes tablets per day } & $\mathrm{M} \pm \mathrm{SD}$ & $1.5 \pm 1.09$ & $1.96 \pm 1.49$ & \multirow{3}{*}{$p=0.031$ * } \\
\hline & Mdn & 1.5 & 2 & \\
\hline & Q.25-Q.75\% & $1-2$ & $1-3$ & \\
\hline \multirow{3}{*}{ Number of all tablets per day } & $\mathrm{M} \pm \mathrm{SD}$ & $7.45 \pm 4.49$ & $7.97 \pm 4.45$ & \multirow{3}{*}{$p=0.586$} \\
\hline & Mdn & 7.5 & 6 & \\
\hline & Q.25-Q.75\% & $3.75-9$ & $5.75-10$ & \\
\hline \multirow{2}{*}{ Sex } & Female & $26(59.09 \%)$ & $75(48.08 \%)$ & \multirow{2}{*}{$p=0.263$} \\
\hline & Male & $18(40.91 \%)$ & $81(51.92 \%)$ & \\
\hline \multirow{2}{*}{ Marital status } & Single & $10(22.73 \%)$ & $55(35.26 \%)$ & \multirow{2}{*}{$p=0.166$} \\
\hline & In a relationship & $34(77.27 \%)$ & $101(64.74 \%)$ & \\
\hline
\end{tabular}


Table 6. Cont.

\begin{tabular}{|c|c|c|c|c|}
\hline \multirow[b]{2}{*}{ Variable } & & \multicolumn{2}{|c|}{$\operatorname{ACDS}^{1}$} & \multirow[b]{2}{*}{$p$} \\
\hline & & $\begin{array}{l}\text { Adherent } \\
(\mathrm{n}=44)\end{array}$ & Non-Adherent $(\mathrm{n}=156)$ & \\
\hline \multirow{4}{*}{ Education } & Elementary & $5(11.36 \%)$ & $16(10.26 \%)$ & \multirow{4}{*}{$p=0.606$} \\
\hline & Vocational & $8(18.18 \%)$ & $41(26.28 \%)$ & \\
\hline & Secondary & $24(54.55 \%)$ & $69(44.23 \%)$ & \\
\hline & Higher & $7(15.91 \%)$ & $30(19.23 \%)$ & \\
\hline \multirow{2}{*}{ Place of residence } & Countryside & $5(11.36 \%)$ & $16(10.26 \%)$ & \multirow{2}{*}{$p=0.786$} \\
\hline & City/town & $39(88.64 \%)$ & $140(89.74 \%)$ & \\
\hline \multirow{4}{*}{ BMI } & Normal weight & $2(4.55 \%)$ & $20(12.82 \%)$ & \multirow{4}{*}{$p=0.441$} \\
\hline & Overweight & $17(38.64 \%)$ & $59(37.82 \%)$ & \\
\hline & Obesity-class 1 & $17(38.64 \%)$ & $48(30.77 \%)$ & \\
\hline & Obesity_class 2 /class 3 & $8(18.18 \%)$ & $29(18.59 \%)$ & \\
\hline \multirow{2}{*}{ Comorbidities: Hypertension } & No & $8(18.18 \%)$ & $31(19.87 \%)$ & \multirow{2}{*}{$p=0.973$} \\
\hline & Yes & $36(81.82 \%)$ & $125(80.13 \%)$ & \\
\hline \multirow{2}{*}{$\begin{array}{l}\text { Comorbidities: } \\
\text { Ischemic heart disease }\end{array}$} & No & $27(61.36 \%)$ & $102(65.38 \%)$ & \multirow{2}{*}{$p=0.754$} \\
\hline & Yes & $17(38.64 \%)$ & $54(34.62 \%)$ & \\
\hline \multirow{2}{*}{$\begin{array}{l}\text { Comorbidities: } \\
\text { Rheumatic diseases }\end{array}$} & No & $33(75.00 \%)$ & $117(75.00 \%)$ & \multirow{2}{*}{$p=1$} \\
\hline & Yes & $11(25.00 \%)$ & $39(25.00 \%)$ & \\
\hline \multirow{2}{*}{$\begin{array}{l}\text { Comorbidities: } \\
\text { Renal diseases }\end{array}$} & No & $39(88.64 \%)$ & $124(79.49 \%)$ & \multirow{2}{*}{$p=0.246$} \\
\hline & Yes & $5(11.36 \%)$ & $32(20.51 \%)$ & \\
\hline \multirow{2}{*}{$\begin{array}{l}\text { Comorbidities: } \\
\text { Respiratory diseases }\end{array}$} & No & $35(79.55 \%)$ & $124(79.49 \%)$ & \multirow{2}{*}{$p=1$} \\
\hline & Yes & $9(20.45 \%)$ & $32(20.51 \%)$ & \\
\hline \multirow{2}{*}{$\begin{array}{l}\text { Comorbidities: } \\
\text { Diseases of the locomotor system }\end{array}$} & No & $28(63.64 \%)$ & $107(68.59 \%)$ & \multirow{2}{*}{$p=0.662$} \\
\hline & Yes & $16(36.36 \%)$ & $49(31.41 \%)$ & \\
\hline \multirow{2}{*}{$\begin{array}{l}\text { Comorbidities: } \\
\text { Diabetic foot syndrome }\end{array}$} & No & $34(77.27 \%)$ & $123(78.85 \%)$ & \multirow{2}{*}{$p=0.987$} \\
\hline & Yes & $10(22.73 \%)$ & $33(21.15 \%)$ & \\
\hline \multirow{2}{*}{$\begin{array}{l}\text { Comorbidities: } \\
\text { Eye diseases }\end{array}$} & No & $23(52.27 \%)$ & $94(60.26 \%)$ & \multirow{2}{*}{$p=0.438$} \\
\hline & Yes & $21(47.73 \%)$ & $62(39.74 \%)$ & \\
\hline \multirow{4}{*}{ Diabetes treatment method } & Oral diabetes medications & $27(61.36 \%)$ & $96(61.54 \%)$ & \multirow{4}{*}{$p=0.885$} \\
\hline & Insulin & $7(15.91 \%)$ & $26(16.67 \%)$ & \\
\hline & Oral medications + insulin & $8(18.18 \%)$ & $30(19.23 \%)$ & \\
\hline & $\begin{array}{l}\text { Non-pharmacological } \\
\text { methods }\end{array}$ & $2(4.55 \%)$ & $4(2.56 \%)$ & \\
\hline
\end{tabular}

Legend: $p$-Mann-Whitney test for quantitative variables, chi-square test or Fisher's exact test for qualitative variables; ${ }^{*}$ statistically significant difference $(p<0.05) ;{ }^{1}$ Adherence in Chronic Diseases Scale; ${ }^{2}$ mean \pm standard deviation; ${ }^{3}$ median; ${ }^{4}$ first quartile and third quartile.

\section{Discussion}

Diabetes is a chronic, progressive disease that affects a patient for the rest of their life. The basis of coping with a chronic disease is its acceptance, which is manifested by a lack of negative emotions related to the disease [24]. Adherence to medical and nutritional recommendations, starting physical activity, and self-control are key factors in avoiding acute and chronic diabetes complications. However, for the elderly, these recommendations are challenging to implement due to the decline in psychophysical fitness with age [13]. As studies on adherence to treatment in older people with T2DM are sparse; we decided to establish the level of adherence, self-care, and disease acceptance in a group of patients over 60 years of age with T2DM, as well as the important predictors of adherence. 


\subsection{Key Results}

The results of our study showed that the majority of elderly patients with T2DM presented an average adherence level, and the independent predictor of qualifying patients to the "non-adherent" group was the level of disease acceptance. In the study group, we observed an average level of disease acceptance, where this level was significantly higher in the group with high adherence compared to the group with low and intermediate adherence. Out of the self-care activities, patients performed worst at glucose and health control, but a positive aspect was that with an increase in the level of disease acceptance, patients' independence in these control areas increased.

\subsection{Interpretation}

4.2.1. Adherence to Treatment Recommendations in Elderly Type 2 Diabetes Mellitus Patients

More than half of our respondents $(57.0 \%)$ had intermediate adherence. Only $22 \%$ of the sample showed high adherence, with $21 \%$ of the sample having low adherence. In the study by Algarni et al. [35] which surveyed patients over 18 years of age with type 1 or T2DM, a group of $134(35.7 \%)$ respondents had high adherence, $161(42.9 \%)$ respondents had intermediate adherence, and $80(21.4 \%)$ respondents had low adherence. Badi et al. [15] found that $15.0 \%$ of respondents with T2DM were highly adherent to diabetes medications, $44.6 \%$ were medium adherent, and $40.4 \%$ showed low adherence

The level of adherence to medications is a significant predictor of HbA1c. However, studies conducted so far showed that the degree of compliance with medical recommendations by diabetic patients is not very satisfactory [36]. In a study on Polish patients with T2DM, Grzywacz et al. [37] showed that $70 \%$ of the respondents did not comply with nutritional recommendations and nearly $40 \%$ were physically inactive]. Mendes et al. [17] reported that $14.9 \%$ of elderly patients with T2DM were non-adherent to medications, $85.1 \%$ were non-adherent to physical activity, and $62.8 \%$ were non-adherent to diet. Polonsky et al. [38] found at least $45 \%$ of patients with T2DM did not achieve adequate glycemic control ( $\mathrm{HbA} 1 \mathrm{c}<7 \%)$. In a Malaysian study, the majority $(79.4 \%)$ of patients had poor diabetes control and $39.6 \%$ of patients had low medication adherence [39]. Others showed that adherence to long-term exercise programs among patients with T2DM can vary between 10 and $80 \%$ and adherence to oral hypoglycemic agents ranged from 36 to 93\% [36]. The CODE-2 (Cost of Diabetes in Europe) study conducted in 2002 found that only $28 \%$ of the patients that were treated for diabetes had normal blood glucose levels [40]. Thus, a disturbing phenomenon is that in almost two decades, the adherence level of T2DM patients did not increase. Given the changes in the approach to patient education, better access to medical services, and modern methods of treatment and self-control, it would be expected that most patients should now demonstrate high levels of adherence. Achieving only an average level of adherence by the elderly may be due to the comorbidities, presence of unacceptable complications, and high levels of anxiety and depression associated with patients of this age [17]. However, our study did not confirm an association between the coexistence of additional chronic diseases and the level of adherence. A large group of our patients suffered from hypertension $(80.5 \%)$, eye diseases $(41.5 \%)$, and ischemic heart disease (35.5\%), but we did not ask our patients about the number of comorbidities. Further studies are warranted to confirm this relationship.

Garcia-Perez et al. [36] showed that the reasons for non-adherence in patients with T2DM are multifactorial and difficult to identify; they included age, information, perception and duration of the disease, complexity of the dosing regimen, polytherapy, psychological factors, safety, tolerability, and cost. The results of our study are consistent, at least in part, with Garcia-Perez et al. [36]. A psychological factor, which is the level of disease acceptance, and other factors, such as the patient's age and the number of diabetes medications, were inherently associated with adherence in our study group. 


\subsubsection{Influence of Disease Acceptance on the Self-Care Level}

One of the goals of our study was to determine the self-care level in the study group and the impact of disease acceptance on it. Self-care is regarded as a cornerstone of diabetes care. Therefore, an accurate assessment of diabetes self-care is crucial for identifying and understanding problem areas in the management of T2DM, facilitating better glucose control, and reducing complications of uncontrolled T2DM [41]. We demonstrated that out of the self-care efforts, our patients scored highest for adherence to health behavior and self-confidence, and worst for glucose control and health control. Our research corresponds to the research of Krzeminska and Czapor [42] where patients with T2DM coped best with the recommendations for proper health behavior, and self-control of glucose levels was the worst. Additionally, in the study by Uchmanowicz et al. [31] Polish patients with T2DM (mean age $61.28 \pm 12.02$ years) dealt best with self-care maintenance (health behavior) and self-care confidence, slightly worse with self-care monitoring, and worst with self-care management. Ausili et al. [30] reported that patients with heart failure and comorbid T2DM performed best in terms of health behavior and self-confidence in managing self-care. In our study, we did not analyze the relationship between the patient's age and the level of self-care, but Ausili et al. [30] showed that patient's age significantly determined the level of self-care, i.e., being older was a risk factor for poor self-care maintenance.

Moreover, our analyses showed that the disease acceptance level was significantly positively correlated with elements of self-care, such as health control $(r=0.186, p=0.009)$ and glucose control $(r=0.201, p=0.004)$; this means that with the increase in disease acceptance, independence of the studied patients increased in these control areas. Given the above, actions should be taken to increase the level of acceptance of a chronic disease, such as diabetes. Since psychophysical fitness decreases with age, the use of psychological and behavioral interventions in the elderly may turn out to be difficult and ineffective. Therefore, it is important to implement a holistic approach to the patient and to undertake comprehensive actions, taking into account the patient's deficits in his or her entire biopsycho-social sphere.

\subsubsection{Influence of Disease Acceptance on the Adherence to Therapeutic Recommendations}

We observed that the level of disease acceptance was a significant independent predictor of the odds of qualifying for non-adherence, where each "disease acceptance point" reduced the odds of qualifying for non-adherence by $9.7 \%$. Along with the increase in disease acceptance, the independence of our subjects in the field of health and glucose control increased. Therefore, there is no doubt that disease acceptance had a very positive effect on important areas of self-control. The patients in our study scored only an average level of disease acceptance. A similar level of disease acceptance in most patients with T2DM was also obtained by Olszak et al. [43], Stefańska and Majda [44], Kurowska and Lach [45] and Bak et al. [46]. Although we did not study the relationship between disease acceptance and patients' age, Olszak et al. [43] showed that lowering the level of disease acceptance was associated with advanced age and a longer duration of the disease. A study by Rogon et al. [27], which was based on patients with T2DM, showed that about $90 \%$ of people over 65 years and 70\% of older men do not accept their disease [46]. In another study, 17\% of patients with T2DM and a mean age of 58.5 years showed a lack of disease acceptance. It should be noted that, with age, the overall functional capacity in everyday life decreases; therefore, elderly patients with chronic diseases may have problems with fully accepting their disease. Adapting to therapeutic recommendations forces patients to make changes in their current lifestyles. They also have to adjust to continuous education and consciously improve their ability to interpret events and cope with new situations. However, the question arises: to what extent are new recommendations in disease management agreed upon and accepted by older people with DM? These recommendations are uncomplicated but they can be difficult to implement because they require much more effort from the patient than taking the recommended medication. The change of usually long-term, incorrect 
eating habits and the correction of a less active lifestyle require a detailed discussion with the patient with the hope of motivating them to take on pro-health activities.

In our study, we also focused on analyses of the relationship between the number of medications taken by a patient and adherence. Leporini et al. [47] argued that the main predictor of non-adherence among the elderly may be the phenomenon of polypharmacy associated with multimorbidities. Many of these patients, due to their reduced cognitive abilities, were not able to adapt to the complex treatment model. Furthermore, a practice that is frequently used by chronically ill patients is self-adjusting drug doses, skipping drug doses, and taking OTC (over-the-counter) medications [47]. The Polish GLUCOMP study showed that high compliance with recommendations was significantly inversely proportional to the number of tablets taken. Therefore, there is a need to pay special attention to limiting the number of tablets prescribed to patients to the necessary minimum [48]. We observed that the number of diabetes medications significantly differentiated patients in the "adherent" and "non-adherent" groups. Patients in the "non-adherent" group took a greater number of diabetes tablets per day compared to the "adherent" group. However, no relationship between adherence and treatment method was observed, which is a finding that is consistent with Alhazmi et al. [49], where no association was found between the type of treatment and medication adherence. In contrast, Algarni et al. [35] reported that the medication regimen was significantly associated with adherence using a univariate analysis. In this study, patients' use of insulin was a predictor of high adherence. As diabetic patients with comorbidities generally have more medications of different pharmacological classes, their complex treatment regimen could be a contributing factor to non-adherence.

The univariate analysis performed in our study showed that age was a factor that significantly differentiated patients in the "adherent" and "non-adherent" groups, where the patients in the "non-adherent" group were significantly older compared to those in the "adherent" group. In the study by Aminde et al. [22], the age of those over 60 years old was an independent predictor of non-adherence among T2DM patients. However, Arulmozhi et al. [50], Al-Haj Mohd et al. [51], and Aloudah et al. [52] all obtained different results. They demonstrated that older age was associated with better oral hypoglycemic agents ${ }^{\prime}$ adherence. Since the described relationship between age and adherence level is different in many studies, it is difficult to draw clear conclusions.

The results of our study also showed that factors such as gender, marital status, education, place of residence, disease duration, BMI, treatment model, and comorbidities did not significantly differentiate both groups in terms of adherence. Slightly different determinants of poor adherence to therapeutic recommendations were indicated by Demoz et al. [14] which were: female sex, presence of chronic diabetes complications, and a lack of formal education. Low educational attainment (or lack thereof) was also a predictor of non-adherence in other studies [19,41,51].

The relationship between disease duration and adherence requires a separate discussion. As mentioned above, the treatment period for diabetes did not differentiate between the "adherent" and "non-adherent" groups, and the regression analysis confirmed that this variable was not a significant predictor of adherence in our study. Contrasting results were obtained by Abebaw et al. [21] and Al-Haj Mohd et al. [51] who showed that the duration of diabetes was significantly associated with the adherence status of the respondents. In the first study, those patients who had been medically diagnosed with diabetes for about three years and above were more likely to be adherent than those with a more recent diagnosis. This could be explained as follows: patients who had been diagnosed with diabetes for a longer duration had more frequent contacts with health facilities and health professionals, which made them more likely to be given repetitive instructions on medication adherence and thus aware of the acute and chronic complications of uncontrolled blood glucose. Moreover, it could be a reflection of wider social interaction with other diabetic patients on antidiabetic medication adherence. Furthermore, in the study conducted in the Arab Emirates mentioned above, the duration of diabetes was a predictor of adherence 
$(\mathrm{OR}=1.830, \mathrm{CI}=1.270$ to $2.636 ; p=0.001$ for every year the duration of diabetes increased) [51].

Inadequate self-care is a global socio-economic problem $[53,54]$ and poses a challenge in the diabetes management strategy for older patients. Until recently, one of the ways to maintain normal blood glucose levels was the self-monitoring of blood glucose (SMBG) with glucose meters. As of now, research by diabetes experts on recommendations for glucose monitoring in patients over 65 years of age confirmed the greater effectiveness of continuous glucose monitoring (CGM) systems. This is particularly due to the benefits in reducing hypoglycemia and improving the times needed to reach target glucose levels, as well as higher satisfaction of the treatment [55-57]. However, due to high costs, they are not readily available to elderly patients living in Poland. In view of the above and the results we obtained demonstrating that patients with T2DM over 60 years of age had problems dealing with individual elements of self-care and adherence, identifying adherence and compliance disruptors turned out to be a key element that should be taken into account when planning educational and psychological interventions for this group of patients.

\subsection{Generalizability}

The potential adherence barriers to therapeutic recommendations were age and the number of diabetes medications. It is worth noting that, first, age is an unmodifiable factor, and second, the treatment of diabetes with monotherapy will not be a proper solution for all patients. In view of the foregoing, undertaking interventions that are aimed at increasing the level of disease acceptance may prove to be the right solution for elderly patients with T2DM, especially those over 69 years of age and taking more than two kinds of diabetes medications a day.

In our study, we observed that with the increase in the level of disease acceptance, the independence of the studied patients in terms of health control and glucose control increased. A previous study showed that barriers to the implementation of interventions that are aimed at increasing the level of disease acceptance in T2DM patients may be: low education and income status, the presence of other chronic illnesses, a recent diagnosis, low social support, low self-efficacy, and pessimistic life orientation [27].

\subsection{Limitations}

The limitations of the study were that the study was conducted in only one province. Only one questionnaire was used to assess adherence. Another limitation of the study was the fact that we did not collect information on the severity of diabetes complications in our patients and on the advancement of comorbidities. The advancement of cardiovascular, cerebrovascular, kidney, nervous system, and eye diseases could have an impact on adherence.

\section{Conclusions}

1. In the vast majority of elderly patients with T2DM, only a moderate or low level of adherence to therapeutic recommendations was observed; therefore, patients who have problems with the full implementation of the treatment plan should be identified as soon as possible and the causes of these problems should be sought.

2. The level of disease acceptance in the study group was average, but it turned out to be an independent predictor of adherence. Therefore, it is justified to use psychological and behavioral interventions that are aimed at increasing the level of diabetes acceptance in the elderly with T2DM. Since psychophysical fitness decreases with age, it is important to implement a holistic approach to the patient and to take comprehensive actions, taking into account the patient's deficits in the entire bio-psycho-social sphere to improve the effectiveness of the undertaken actions.

3. Out of the self-care activities that were investigated, the patients were the worst at glucose and health control. However, on the positive side, patients' self-reliance in these control areas increased as the level of disease acceptance increased. Thus, the 
obtained result confirmed the legitimacy of interventions that are aimed at increasing the level of disease acceptance in this group of patients.

Supplementary Materials: The following are available online at https:/ / www.mdpi.com/article/10 .3390/ijerph18168658/s1. Table S1: The Acceptance of Illness Scale (AIS), Table S2: The Self-Care of Diabetes Inventory (SCODI), Table S3: The Adherence Scale in Chronic Diseases (ACDS).

Author Contributions: I.B., K.S. and I.U.: Conceptualization, Formal analysis, Investigation; I.B. and K.S.: Methodology; I.B. and I.U.: Project administration; K.S.: Resources; I.B. and K.S.: Writingoriginal draft; I.U.: Writing-review \& editing. All authors have read and agreed to the published version of the manuscript.

Funding: This research received internal funding from the University of Zielona Góra, Poland.

Institutional Review Board Statement: The approval of the Bioethics Committee at the Medical University of Wrocław (approval number KB-207/2018) was obtained and the requirements of the Helsinki Declaration of 1975 (amended in 2000) and Good Clinical Practice were met.

Informed Consent Statement: Informed consent was obtained from all patients involved in the study.

Data Availability Statement: Data confirming the reported results can be found at the Department of Nursing of the University of Zielona Góra. Responsible person: Iwona Bonikowska.

Acknowledgments: The authors thank all those who participated in the study.

Conflicts of Interest: The authors declare no conflict of interest.

\section{References}

1. Saeedi, P.; Petersohn, I.; Salpea, P.; Malanda, B.; Karuranga, S.; Unwin, N.; Colagiuri, S.; Guariguata, L.; Motala, A.A.; Ogurtsova, K.; et al. IDF Diabetes Atlas Committee. Global and regional diabetes prevalence estimates for 2019 and projections for 2030 and 2045: Results from the International Diabetes Federation Diabetes Atlas, 9th edition. Diabetes Res. Clin. Pract. 2019, 157, 107843. [CrossRef] [PubMed]

2. Kolb, H.; Martin, S. Environmental/lifestyle factors in the pathogenesis and prevention of type 2 diabetes. BMC Med. 2017, 15, 131. [CrossRef] [PubMed]

3. Sinclair, A.; Saeedi, P.; Kaundal, A.; Karuranga, S.; Malanda, B.; Williams, R. Diabetes and global ageing among 65-99-year-old adults: Findings from the International Diabetes Federation Diabetes Atlas, 9th edition. Diabetes Res. Clin. Pract. 2020, $162,108078$. [CrossRef]

4. National Health Fund. Department of Analysis and Strategy. NHF about Health. Diabetes. Warsaw 2019. Available online: https:/ / zdrowedane.nfz.gov.pl/course/view.php?id=45/ (accessed on 19 January 2020).

5. Williams, R.; Karuranga, S.; Malanda, B.; Saeedi, P.; Basit, A.; Besançon, S.; Bommer, C.; Esteghamati, A.; Ogurtsova, K.; Zhang, P.; et al. Global and regional estimates and projections of diabetes-related health expenditure: Results from the International Diabetes Federation Diabetes Atlas, 9th edition. Diabetes Res. Clin. Pract. 2020, 162, 108072. [CrossRef]

6. Bello-Chavolla, O.Y.; Rojas-Martinez, R.; Aguilar-Salinas, C.A.; Hernández-Avila, M. Epidemiology of diabetes mellitus in Mexico. Nutr. Rev. 2017, 75, 4-12. [CrossRef]

7. Huang, E.S.; Laiteerapong, N.; Liu, J.Y.; John, P.M.; Moffet, H.H.; Karter, A.J. Rates of complications and mortality in older patients with diabetes mellitus: The diabetes and aging study. JAMA Intern. Med. 2014, 174, 251-258. [CrossRef]

8. Corriere, M.; Rooparinesingh, N.; Kalyani, R.R. Epidemiology of diabetes and diabetes complications in the elderly: An emerging public health burden. Curr. Diab. Rep. 2013, 13, 805-813. [CrossRef]

9. Kirkman, M.S.; Briscoe, V.J.; Clark, N.; Florez, H.; Haas, L.B.; Halter, J.B.; Huang, E.S.; Korytkowski, M.T.; Munshi, M.N.; Odegard, P.S.; et al. Diabetes in older adults. Diabetes Care 2012, 35, 2650-2664. [CrossRef]

10. Salehidoost, R.; Mansouri, A.; Amini, M.; Aminorroaya Yamini, S.; Aminorroaya, A. Diabetes and all-cause mortality, a 18-year follow-up study. Sci. Rep. 2020, 10, 3183. [CrossRef]

11. Wright, A.K.; Kontopantelis, E.; Emsley, R.; Buchan, I.; Sattar, N.; Rutter, M.K.; Ashcroft, D.M. Life Expectancy and Cause-Specific Mortality in Type 2 Diabetes: A Population-Based Cohort Study Quantifying Relationships in Ethnic Subgroups. Diabetes Care 2017, 40, 338-345. [CrossRef]

12. Clua-Espuny, J.L.; González-Henares, M.A.; Queralt-Tomas, M.; Campo-Tamayo, W.; Muria-Subirats, E.; Panisello-Tafalla, A.; Lucas-Noll, J. Mortality and Cardiovascular Complications in Older Complex Chronic Patients with Type 2 Diabetes. Biomed Res. Int. 2017, 2017, 6078498. [CrossRef]

13. American Diabetes Association. 4. Lifestyle Management: Standards of Medical Care in Diabetes-2018. Diabetes Care 2018, 41, 38-50. [CrossRef] 
14. Demoz, G.T.; Wahdey, S.; Bahrey, D.; Kahsay, H.; Woldu, G.; Niriayo, Y.L.; Collier, A. Predictors of poor adherence to antidiabetic therapy in patients with type 2 diabetes: A cross-sectional study insight from Ethiopia. Diabetol. Metab. Syndr. 2020, 12, 62. [CrossRef] [PubMed]

15. Badi, S.; Abdalla, A.; Altayeb, L.; Noma, M.; Ahmed, M.H. Adherence to Antidiabetic Medications Among Sudanese Individuals with Type 2 Diabetes Mellitus: A Cross-Sectional Survey. J. Patient Exp. 2020, 7, 163-168. [CrossRef]

16. Al-Sahouri, A.; Merrell, J.; Snelgrove, S. Barriers to good glycemic control levels and adherence to diabetes management plan in adults with Type-2 diabetes in Jordan: A literature review. Patient Prefer. Adherence 2019, 13, 675-693. [CrossRef] [PubMed]

17. Mendes, R.; Martins, S.; Fernandes, L. Adherence to Medication, Physical Activity and Diet in Older Adults with Diabetes: Its Association with Cognition, Anxiety and Depression. J. Clin. Med. Res. 2019, 11, 583-592. [CrossRef] [PubMed]

18. Sabate, E. Adherence to Long Term Therapies: Evidence for Action; World Health Organization: Geneva, Switzerland, 2003; pp. 1-10.

19. Jemal, A.; Abdela, J.; Sisay, M. Adherence to Oral Antidiabetic Medications among Type 2 Diabetic (T2DM) Patients in Chronic Ambulatory Wards of Hiwot Fana Specialized University Hospital, Harar, Eastern Ethiopia: A Cross Sectional Study. J. Diabetes Metab. 2017, 8, 721. [CrossRef]

20. Tadele, K.; Abebe, A.; Teklebirhan, T.; Desalegn, S. Assessment of adherence to insulin self-administration and associated factors among type I diabetic patients at Jimma University Specialized Hospital, Ethiopia. Endocrinol. Diabetes Res. 2017, 3. [CrossRef]

21. Abebaw, M.; Messele, A.; Hailu, M.; Zewdu, F. Adherence and Associated Factors towards Antidiabetic Medication among Type II Diabetic Patients on Follow-Up at University of Gondar Hospital, Northwest Ethiopia. Adv. Nurs. 2016, 1, 1-7. [CrossRef]

22. Aminde, L.N.; Tindong, M.; Ngwasiri, C.A.; Aminde, J.A.; Njim, T.; Fondong, A.A.; Takah, N.F. Adherence to antidiabetic medication and factors associated with non-adherence among patients with type-2 diabetes mellitus in two regional hospitals in Cameroon. BMC Endocr. Disord. 2019, 19, 35. [CrossRef]

23. Jaam, M.; Awaisu, A.; Mohamed Ibrahim, M.I.; Kheir, N. A holistic conceptual framework model to describe medication adherence in and guide interventions in diabetes mellitus. Res. Soc. Adm. Pharm. 2018, 14, 391-397. [CrossRef] [PubMed]

24. Besen, D.B.; Esen, A. Acceptance of Illness and Related Factors in Turkish Patients with Diabetes. Soc. Behavr. Pers. 2012, 40, 1597-1610. [CrossRef]

25. Lewis, K.S. Emotional adjustment to a chronic illness. Lippincott's Prim. Care. Pract. 1998, 2, 38-51.

26. Stanton, A.L.; Revenson, T.A.; Tennen, H. Health Psychology: Psychological Adjustment to Chronic Disease. Annu. Rev. Psychol. 2007, 58, 565-592. [CrossRef]

27. Rogon, I.; Kasprzak, Z.; Szcześniak, Ł. Perceived quality of life and acceptance of illness in people with type 2 diabetes mellitus. Prz. Menopauzalny 2017, 16, 79-85. [CrossRef]

28. Juczyński, Z. Narzędzia Pomiaru W Promocji I Psychologii Zdrowia; Wydanie II; Pracownia Testów Psychologicznych Polskiego Towarzystwa Psychologicznego: Warszawa, Poland, 2012.

29. NFZ-Zatacznik nr 1 Do Pisma Znak; WSOZ-II.0123.28.2018; National Health Fund: Warszawa, Poland, 2018.

30. Ausili, D.; Barbaranelli, C.; Rossi, E.; Rebora, P.; Fabrizi, D.; Coghi, C.; Luciani, M.; Vellone, E.; Di Mauro, S.; Riegel, B. Development and Psychometric Testing of a Theory-Based Tool to Measure Self-Care in Diabetes Patients: The Self-Care for Diabetes Inventory. BMC Endocr. Disord. 2017, 17, 66. [CrossRef]

31. Uchmanowicz, I.; Krzemińska, S.; Ausili, D.; Luciani, M.; Lisiak, M. Polish Adaptation of the Self-Care of Diabetes Inventory (SCODI). Patient Prefer. Adherence 2020, 14, 1341-1350. [CrossRef]

32. Kubica, A.; Kosobucka, A.; Michalski, P.; Pietrzykowski, Ł.; Jurek, A.; Wawrzyniak, M.; Kasprzak, M. Skala adherence w chorobach przewlekłych-Nowe narzędzie do badania realizacji planu terapeutycznego. Folia Cardiol. 2017, 12, 19-26.

33. Central Statistical Office. Relative Concepts in Official Statistics: Older People; Poland; 2017. Available online: https://stat.gov. pl/metainformacje/slownik-pojec/pojecia-stosowane-w-statystyce-publycznej/3928,pojecie.html/ (accessed on 4 April 2018).

34. Centers for Disease Control and Prevention. Defining Adult Overweight \& Obesity. Available online: https://www.cdc.gov/ obesity /adult/defining.html (accessed on 19 July 2021).

35. Alqarni, A.M.; Alrahbeni, T.; Qarni, A.A.; Qarni, H.M.A. Adherence to diabetes medication among diabetic patients in the Bisha governorate of Saudi Arabia-A cross-sectional survey. Patient Prefer. Adherence 2018, 24, 63-71, Erratum in 2019, 13, 249. [CrossRef]

36. García-Pérez, L.E.; Alvarez, M.; Dilla, T.; Gil-Guillén, V.; Orozco-Beltrán, D. Adherence to therapies in patients with type 2 diabetes. Diabetes Ther. 2013, 4, 175-194. [CrossRef]

37. Grzywacz, A.; Śliż, D. Assessment of adherence to physician recommendations among patients with diagnosed diabetes mellitus type 2. Folia Cardiol. 2020, 3, 210-218. [CrossRef]

38. Polonsky, W.H.; Henry, R.R. Poor medication adherence in type 2 diabetes: Recognizing the scope of the problem and its key contributors. Patient Prefer. Adherence 2016, 10, 1299-1307. [CrossRef]

39. Balasubramaniam, S.; Lim, S.L.; Goh, L.H.; Subramaniam, S.; Tangiisuran, B. Evaluation of illness perceptions and their associations with glycaemic control, medication adherence and chronic kidney disease in type 2 diabetes mellitus patients in Malaysia. Diabetes Metab. Syndr. 2019, 13, 2585-2591. [CrossRef]

40. Massi-Benedetti, M. CODE-2 Advisory Board. The cost of diabetes Type II in Europe: The CODE-2 Study. Diabetologia 2002, 45, 1-4. [CrossRef]

41. Lu, Y.; Xu, J.; Zhao, W.; Han, H.R. Measuring Self-Care in Persons with Type 2 Diabetes: A Systematic Review. Eval. Health Prof. 2016, 39, 131-184. [CrossRef] [PubMed] 
42. Krzemińska, S.; Czapor, E. The level of self-care in patients with T2 diabetes using the Self-Care of Diabetes Inventory (SCODI) questionnaire. Mod. Nurs. Health Care 2019, 8, 109-114.

43. Olszak, C.; Nowicka, E.; Baczewska, B.; Łuczyk, R.; Kropornicka, B.; Krzyżanowska, E.; Daniluk, J. The influence of selected socio-demographic and medical factors on the acceptance of illness in a group of patients with type 2 diabetes mellitus. J. Educ. Health Sport 2016, 6, 11-28.

44. Stefańska, M.; Majda, A. Religiousness and acceptance of the disease among persons with diabetes. Pol. Nurs. 2019, 2, 156-164.

45. Kurowska, K.; Lach, B. Akceptacja choroby i sposoby radzenia sobie ze stresem u chorych na cukrzyce typu 2. Diabetol. Pract. 2011, 12, 113-119. (In Polish)

46. Bak, E.; Marcisz, C.; Krzemińska, S.; Dobrzyn-Matusiak, D.; Foltyn, A.; Drosdzol-Cop, A. Relationships of Sexual Dysfunction with Depression and Acceptance of Illness in Women and Men with Type 2 Diabetes Mellitus. Int. J. Environ. Res. Public Health 2017, 14, 1073. [CrossRef]

47. Leporini, C.; De Sarro, G.; Russo, E. Adherence to therapy and adverse drug reactions: Is there a link? Expert. Opin. Drug. Saf. 2014, 13, 41-55. [CrossRef]

48. Strojek, K.; Kurzeja, A.; Gottwald-Hostalek, U. Patient adherence to and tolerability of treatment with metformin extended-release formulation in patients with type 2 diabetes. GLUCOMP study. Clin. Diabetol. 2016, 5, 15-21. [CrossRef]

49. Alhazmi, T.; Sharahili, J.; Khurmi, S.; Zughbi, T.; Alrefai, M.; Hakami, M.; Wasili, F.; Wadani, M.S.; Sahli, S.; Alhazmi, A.H.; et al. Drug Compliance among Type 2 Diabetic patients in Jazan Region, Saudi Arabia. Int. J. Adv. Res. 2017, 5, 966-974. [CrossRef]

50. Arulmozhi, S.; Mahalakshmy, T. Self Care and Medication Adherence among Type 2 Diabetics in Puducherry, Southern India A Hospital Based Study. J. Clin. Diagn. Res. 2014, 8, 1-3.

51. Al-Haj Mohd, M.M.; Phung, H.; Sun, J.; Morisky, D.E. The predictors to medication adherence among adults with diabetes in the United Arab Emirates. J. Diabetes Metab. Disord. 2016, 9, 15-30. [CrossRef]

52. Aloudah, N.M.; Scott, N.W.; Aljadhey, H.S.; Araujo-Soares, V.; Alrubeaan, K.A.; Watson, M.C. Medication adherence among patients with Type 2 diabetes: A mixed methods study. PLOS ONE 2018, 13, e0207583.

53. Sedlar, N.; Lainscak, M.; Mårtensson, J.; Strömberg, A.; Jaarsma, T.; Farkas, J. Factors related to self-care behaviours in heart failure: A systematic review of European Heart Failure Self-Care Behaviour Scale studies. Eur. J. Cardiovasc. Nurs. 2017, 16, 272-282. [CrossRef]

54. Malhotra, C.; Foo, R.; Singh, R.; Ozdemir, S.; Teo, I.; Sim, D.; Jaufeerally, F.; Aung, T.; Keong, Y.K.; Nadkarni, N.; et al. Study protocol for a cohort study of patients with advanced heart failure in Singapore. BMJ Open 2018, 8, e022248. [CrossRef]

55. Szadkowska, A.; Zozulińska-Ziółkiewicz, D.; Walczak, M.; Cyganek, K.; Wolnik, B.; Gawrecki, A.; Myśliwiec, M. Expert opinion: Implantable continuous glucose monitoring system-An innovation in the treatment of diabetes. Clin. Diabetol. 2019, 8, 318-328. (In Polish) [CrossRef]

56. American Diabetes Association. 6. Glycemic Targets: Standards of Medical Care in Diabetes-2019. Diabetes Care 2019, 42, 61-70. [CrossRef]

57. Bruttomesso, D.; Laviola, L.; Avogaro, A.; Bonora, E.; Del Prato, S.; Frontoni, S.; Orsi, E.; Rabbone, I.; Sesti, G.; Purrello, F. The Italian Diabetes Society (SID). The use of real time continuous glucose monitoring or flash glucose monitoring in the management of diabetes: A consensus view of Italian diabetes experts using the Delphi method. NMCD 2019, 29, 421-431. [PubMed] 